\section{Food safety in food services in Lombardy: proposal for an inspection-scoring model}

Claudia M. Balzaretti, ${ }^{1}$ Katia Razzini, ${ }^{2}$ Silvia Ziviani, ${ }^{3}$ Sabrina Ratti, ${ }^{1}$ Vesna Milicevic, ${ }^{4}$ Luca M. Chiesa, ${ }^{1}$ Sara Panseri, ${ }^{1}$ Marta Castrica ${ }^{1}$

${ }^{1}$ Departement of Health, Animal Science and Food Safety, University of Milan; ${ }^{2}$ Italian Union of Inspection Sanitary Personnel; ${ }^{3}$ Freelance veterinary surgeon, Milan; ${ }^{4}$ Health Protection Agency, Metropolitan City of Milan, Milan, Italy

\begin{abstract}
The purpose of this study was to elaborate a checklist with an inspection scoring system at national level in order to assess compliance with sanitary hygiene requirements of food services. The inspection scoring system was elaborated taking into account the guidelines drawn up by NYC Department of Food Safety and Mental Hygiene. Moreover the checklist was used simultaneously with the standard inspection protocol adopted by Servizio Igiene Alimenti Nutrizione (Servizio Igiene Alimenti Nutrizione - Ss. I.A.N) and defined by D.G.R 6 March 2017 - n. X/6299 Lombardy Region. Ss. I.A.N protocol consists of a qualitative response according to which we have generated a new protocol with three different grading: $\mathrm{A}, \mathrm{B}$ and $\mathrm{C}$. The designed checklist was divided into 17 sections. Each section corresponds to prerequisites to be verified during the inspection. Every section includes the type of conformity to check and the type of violation: critical or general. Moreover, the failure to respect the expected compliance generates 4 severity levels that correspond to score classes. A total of 7 food services were checked with the two different inspection methods. The checklist results generated a food safety score for each food service that ranged from 0.0 (no flaws observed) to 187.2, and generates three grading class: A (0.0-28.0); B (29.0 - 70.0) and C (>71.00). The results from the Ss. I. A. N grading method and the checklist show positive correlation $(r=0.94, \mathrm{P}>0.01)$ suggesting that the methods are comparable. Moreover, our scoring checklist is an easy and unique method compared to standard and allows also managers to perform effective surveillance programs in food service.
\end{abstract}

\section{Introduction}

The publication of inspection results is a practice already adopted by several nonEuropean countries (Razzini and Balzaretti, 2015), particularly in United States of America (USA), with the aim of creating a direct information channel between competent authority and final consumers to know the sanitary level of the food services in clear and transparent way.

The concept of $\mathrm{ABC}$ grading system concerning aspect of public hygiene was born in the USA in 1920 when the U. S. Public Health Service (U. S. Public Health Service - USPHS) created the first voluntary application code, called Model Milk Code.

This code had the objective to provide information on the safety of milk production processes communicating the safety grade through a letter: A, B or C applied directly on the bottles (McDean, 1997).

Subsequently based on this model in 1932, was created the first Model Food Code for food services.

From 1932 to today, the Grade Card System has developed in several countries and has been adopted at the international level, showing to be a model that assists food control jurisdictions by providing them with a scientific technical and legal basis for evaluating the retail and food service segment of the industry.

As far as Europe, the foodborne diseases are still a major concern, taking into account that $60 \%$ of foodborne outbreaks in Europe occur outside the home and $22 \%$ take place a collective (Roncesvalles et al., 2017).

Therefore, the impact of catering services on public health is determinant in order to protect the health of final consumers, for this reason through the Regulation (EC) No. 852/2004 Europe requires to food business operators to apply procedures based on hazard analysis and critical control points (hazard analysis and critical control points - HACCP) principles.

Despite this, a well-defined regulatory framework and the current contest see different situations in comparison, on one hand the difficulties of small and medium catering in the implementation of self- control system for different reason such us limited human resource, insufficient knowledge that lead to incorrect food preparation practices (Roncesvalles et al., 2017).

On the other hand, at European level is still missing, especially in Italy, an inspection control model easy and unique able to perform effective surveillance programs in food service. Moreover the growing demand of consumers in wanting to know the sanitary level of the catering services and inspection scores has already brought many European countries such as Denmark
Correspondence: Marta Castrica, Department of Health, Animal Science and Food Safety (VESPA), University of Milan, Via Celoria 10, 20133 Milan, Italy.

Phone: +390050317857.

E-mail: marta.castrica@unimi.it

Key words: Scoring method; grading system; food service inspection.

Received for publication: 14 July 2017. Revision received: 3 October 2017. Accepted for publication: 6 October 2017

This work is licensed under a Creative Commons Attribution-NonCommercial 4.0 International License (CC BY-NC 4.0).

(C) Copyright C.M. Balzaretti et al., 2017

Licensee PAGEPress, Italy

Italian Journal of Food Safety 2017; 6:6915

doi:10.4081/ijfs.2017.6915

and Belgium to apply systems that can be traced back to USA ones (Razzini and Balzaretti, 2015).

Actually, in Italy, in particular in Lombardy region, the control system is based on a standard protocol adopted by Ss. I A $\mathrm{N}$ and defined by decree of regional junta (D.G.R) 6 March 2017 n. X/6299.

The Operational Manual of Local Competent Authorities on Official Controls on Food Safety (Manuale Operativo delle Autorità Competenti Locali), was draw up in accordance with the Regulation (EC) No. $882 / 2204$.

The control system should be based on documented procedures [Reg. (EC) no.882/2004, art.8 (1)] in order to guarantee the transparency of the official controls and the homogenous evaluation of food business operators capacities to ensure compliance with the requirements laid down in the current European legislation.

Following the application of the manual during an inspection, the data collected are processed, and the results are released in the form of descriptive verbal.

This qualitative method is difficult to understand for the final consumer compared to an inspection score and grading system, for this reason, the development of an experimental protocol (checklist) for the application in Italy of a grading system represents a useful model for the competent authorities and easy-to-use tool for the final consumers.

Moreover, the use of a grading model is useful for the food business operators in identifying the area resulted critically.

Different authors (Roncesvalles et al., 2017; Razzini and Balzaretti, 2015; Da Cunha et al., 2016) show the efficiency of 
using inspection score and grading system for evaluation of the food services quality.

The checklist method is an instrument easily to use to evaluate food safety performance due to its reproducibility, cost-effectiveness and practically (Da Cunha et al., 2016); further the checklist may be a useful method for the food services in undertaking a course of self-management and measurable improvement.

The aim of this study was to elaborate at national level, starting from Lombardy a checklist with an inspection score and grading, in order to assess compliance with sanitary hygiene requirements of food services and to make the results available to the final consumer.

Finally, can represent a valuable system for both the competent authority during the official controls and for food business operators as self-testing tool.

The checklist was elaborated taking into account the guidelines drawn up by NYC Department of Food Safety and Mental Hygiene (City of New York-Department of Health and Mental Hygiene, 2007).

\section{Materials and Methods}

\section{Sample collection}

The study involved seven food services located in Italy in particular in the Lombardy region. All these establishments have a HACCP system and they revised periodically the auto-control plan; restaurants $(n=2)$, bar that administer food in the cold chain $(n=2)$, bar that administer food in the cold chain and with pastry laboratory $(n=2)$ and one delicatessen that administer food in the hot chain.

The same trained people visited each food service during the study and the onsite inspection consisted of data collection using two different methods: (i) checklist with a scoring system and (ii) standard inspection protocol normally adopted by Ss. I. A. N.

\section{Structure of checklist}

The authors developed a specific checklist and are willing to provide the integral model of checklist for potential further applications into a shared research projects.

The checklist was subdivided into 17 sections; each section represents a prerequisite to be verified during the on-site inspection, the Table 1 lists all sections described in the checklist.

Each section was further subdivided into subsections called procedural compliances, which are to be verified through onsite observation.
To each procedural compliance, it corresponds: (i) the type of the violation, which may be critical or general and (ii) four score classes that was assigned different violation points.

\section{Definition of score}

Each evaluation class corresponds to a baseline violation score: (i) score class one: assignment of 2 violation points, (ii) score class two: assignment of 4 violation points, (iii) score class three: 6 assignment of 6 violation points, and (iv) score class four: assignment of 10 violation points.

Moreover, when the violation is critical, a factor of 1.5 is multiplied with the baseline violation score obtained in each category.

In addition the observance of some categories is of greater importance than others, for this reason, to each category was assigned a factor $X$ with range of 0.6 (not very relevant category) to 1.0 (relevant category) (Table 2).

\section{Standard inspection protocol}

The Operational Manual of Local Competent Authorities on Official Controls on Food Safety adopted by Ss. I. A. N was draw up in according to the Legislative Decree No. 193/2007 and in accordance with the requirements described in the Regulation (EC) No. 882/2004.

The manual defines the standards oper-

Table 1. Checklist structure.

\begin{tabular}{lcc} 
Sections & Items & Number of subsections \\
1 & Administrative parameters and HACCP & 9 \\
2 & Temperature management & 8 \\
\hline 3 & Food supply system & 2 \\
4 & Acceptability of foodstuffs and hygiene of food handling activities & 8 \\
\hline 5 & Water supply system & 3 \\
\hline 6 & Waste management procedure & 6 \\
\hline 7 & Food operators training & 2 \\
\hline 8 & Food handlers hygiene & 9 \\
\hline 9 & Cleaning and sanitation procedures & 6 \\
\hline 10 & Weed control procedures & 6 \\
\hline 11 & Local design control & 11 \\
12 & Organization of the premises & 10 \\
\hline 13 & Management organization and maintenance & 5 \\
14 & Control area feeding & 3 \\
\hline 15 & Personal dressing area control & 4 \\
16 & Personal area toilet control & 5 \\
\hline 17 & Client area toilet control & 5
\end{tabular}

HACCP, Hazard Analysis and Critical Control Points.

Table 2. Assigning factor $\mathrm{X}$ in relation to category.

\begin{tabular}{lccccccccccccccccc}
\hline Section & 1 & 2 & 3 & 4 & 5 & 6 & 7 & 8 & 9 & 10 & 11 & 12 & 13 & 14 & 15 & 16 & 17 \\
Factor X & 1 & 1 & 1 & 1 & 0.8 & 0.6 & 0.8 & 1 & 1 & 1 & 0.8 & 1 & 1 & 0.6 & 0.6 & 0.6 & 0.6 \\
\hline
\end{tabular}

ating procedures that competent authorities should carry out during the official control, and has the following objectives: i) recognize a risk categorization system related to the characteristics of productive activities, food, feed and the health status of food-producing animals; ii) design an audit system that acts in the context of continuous improvement of control activities; iii) review, periodically, the system for collecting, processing and evaluating control data; iv) develop competence in official controls in the field of food safety, animal health and welfare, According to quality management and quality assurance, in relation to the Regulation (EC) No. 882/2004.

The results of the inspection were released in the form of descriptive verbal and after analysis, the authors, based on the overall conclusions contained in each verbal, divided the inspections into three categories, assigning a grading: A, B and C.

The assignment of letter A, was reserved to food services which overall had have not non- compliance (accordance with the requirement), while the letter $\mathrm{B}$, was reserved for food services that had have minor non-compliance (consistent with the objective of improving) and finally the letter $\mathrm{C}$ was assigned to food services that had have a stringent non-conformity (non- compliance).

Analysis of verbal and the subsequent 
subdivision in categories was designed according to the guidelines for official control under the European regulations (EC) No. 854/2004 and 882/2004 (European Commission, 2004a, 2004b).

Moreover, the authors taking into account the proposal of a grading elaborated by NYC Department of Health and Mental Hygiene.

\section{Statistical analysis}

A statistical program (SPSS for Windows, release 11.0.1, SPSS, Inc., Chicago, IL, USA) was used for data processing. In order to find a significant correlation between the grading defined based on standard protocol and checklist was calculated the Pearson coefficient.

\section{Results}

In Table 3 the results obtained with both methods (checklist and grading) are presented.

For the food service 2, which received the grading A (checklist score $=0.0$ ), the competent authorities (ATS Metropolitan City of Milan) have expressed a judgment of complete conformity because during the on-site inspection non-compliance has been observed and therefore they have not indicated a corrective actions.

Instead, as regards the food service 5, which has also received the grading $\mathrm{A}$ (checklist score $=7.2$ ), the competent authorities prescribed of one non-compliance according to the Legislative Decree No. 193/2007 subparagraph 7.

On food services 3,4 and 7 , which received the grading $\mathrm{B}$ (checklist scores $=$ $31.00,50.2$ and 30.0 respectively) the HACCP managers of the food services establishments directly provided the correction of non-compliance, that in any case did not lead to a potential risks (Legislative Decree No. 193/2007 subparagraph 7).

In conclusion in food services 1 and 6 , which received the grading $\mathrm{C}$ (checklist scores $=80.00$ and 187.2 respectively), were found a non-compliance that put the food safety of food at risk.

In both cases, the competent authorities has suspended the food service activities according to the Reg. (EC) No. 882/2004, Article 54 until to the rehabilitation of proper hygienic conditions of the activities.

Moreover, the competent authorities imposed in both cases the administrative sanctions under the Legislative Decree No. 193/2007 (subparagraph 5).

Finally, by comparing the grading results obtained by the Ss. I. A. N. verbal whit the score obtained with the checklist it was possible to assign a range to the three grading classes: A $(0.0-28.0)$, B (29.070.0) and $C$ (more than 71.00). A higher correlation between the grading classes and the range score assigned was observed ( $r=$ $0.94)$ and the correlation value $(r)$ confirms the hypothesis that the results of the Ss. I. A. $N$. verbal are perfectly overlapping with the inspection score model which came out of our checklist.

\section{Discussion}

The development of a food safety strategy based on an inspection score and grading system to evaluate the food service establishments has been promoted due to the results obtained in this study and different authors have confirmed that: (i) the inspection score model allows a preventive approach in identifying potential risks, as observed in other study conducted in different places (Buchhloz et al., 2002; Da Cunha et al., 2014; Zablotsky Kufel et al., 2011); (ii) the model is able to communicate directly and unequivocally to the final consumers the hygiene and health level of food service, moreover (iii) this evaluation model may promote a healthy competition among food services, quality managers and food business operators (Da Cunha et al., 2016).

Another positive aspect derived from the application of inspection score model and grading system could be useful for not only for the competent authorities but also for quality managers of food service to put into action self-management procedures and in the implementation of HACCP plan (City of New York - Department of Health and Mental hygiene, 2012).

From the evaluation of different checklists produced by several authors (Da Cunha et al., 2016; Fielding et al., 2001; Buchhloz et al., 2002; Fillon and Powell, 2009) might be possible the creation of a standardized assessment model for health surveillance, with the dual objectives of development of a direct communication channel with the final consumers and to facilitate the surveillance work of the competent authorities.

\section{Conclusions}

This confirms that the renovation of standard restaurants inspection program could be possible if each player involved in the food services are willing to make public the real hygiene and health level. Moreover, the final consumers seems to be prepared to accept this new food service grading, as has already been observed in other countries such as in Campania region (Decreto Dirigenziale No. 77, published 23.11.2007) that has already made a checklist for the official control of the food industries. In conclusion, the Italian government should invest scientifically and financially in health surveillance by promoting a new inspection model such as the introduction of a standardized inspection score system in order to adopt strategies at the forefront that allow the reduction of the risk of transmitting foodborne disease in order to protect the health consumers and citizen.

Table 3. Checklist results compared to the verbal result.

\begin{tabular}{|c|c|c|c|c|}
\hline $\begin{array}{l}\text { Food } \\
\text { service }\end{array}$ & $\begin{array}{l}\text { Type of food } \\
\text { service }\end{array}$ & $\begin{array}{l}\text { Final checklist } \\
\text { score }\end{array}$ & $\begin{array}{l}\text { Grading } \\
\text { assigned }\end{array}$ & Verbal results \\
\hline 1 & Restaurant & 80.0 & $\mathrm{C}$ & $\begin{array}{l}\text { Suspension of food service activities } \\
\text { with administrative sanction }\end{array}$ \\
\hline 2 & Restaurant & 0.0 & A & Complete conformity \\
\hline 3 & Bar that administers food in cold chain & 31.0 & B & $\mathrm{N}=3$ minor non conformity that does not involve risks \\
\hline 4 & Bar that administers food in cold chain & 50.2 & B & Minor non conformity that does not involve risks \\
\hline 5 & Bar that administers food in cold chain and with pastry laboratory & 7.2 & A & $\mathrm{N}=1$ minor non-conformity \\
\hline 6 & Bar that administers food in cold chain and with pastry laboratory & 187.2 & $\mathrm{C}$ & $\begin{array}{l}\text { Suspension of food service activities } \\
\text { with administrative sanction }\end{array}$ \\
\hline 7 & Delicatessens that administer food in hot chain & 30.0 & B & $\mathrm{N}=4$ minor non conformity that does not involve risks \\
\hline
\end{tabular}




\section{References}

Buchholz U, Run G, Kool JL, Fielding J, Mascola, 2002. A risk-based restaurant inspection system in Los Angeles County. J Food Prot 65:367-72.

City of New York-Department of Health Mental Hygiene, 2007. Inspection scoring system for food service establishments. Departament of Health and Mental Hygiene, New York, NY, USA.

City of New York-Departament of Health Mental Hygiene, 2012. Restaurant grading in New York City at 18 months public. Departament of Health and Mental Hygiene, New York, NY, USA.

Da Cunha DT, De Freitas Saccol AL, Tondo EC, De Oliveira AB., Ginani VC, Araújo CV, Stedefeldt E, 2016. Inspection score and grading system for food services in Brazil: the results of a food safety strategy to reduce the risk of foodborne diseases during the 2014 FIFA World Cup. Front microbiol 7:110.

Da Cunha DT, De Oliveira ABA, De Freitas Saccol AL, Tondo EC, Silva EA, Jr Ginani VC, 2014. Food safety of food services within the destinations of the 2014 FIFA World Cup in Brazil:
Development and reliability assessment of the official evaluation instrument. Food Res Int 57:95-103.

European Commission, 2004a. Regulation of the European Parliament and of the Council of 29 April 2004 laying down specific rules for the organization of official controls on products of animal origin intended for human consumption, 854/2004/CE. In: Official Journal, L 226/83, 25/06/2004.

European Commission, 2004b. Regulation of the European Parliament and of the Council of 29 April 2004 on official controls performed to ensure the verification of compliance with feed and food law, animal health and animal welfare rules, 882/2004/CE. In: Official Journal, L 165/1, 30/04/2004.

Fielding JE, Aguirre A, Palaiologos E, 2001. Effectiveness of altered incentives in a food safety inspection program. Prev Med 32:239-44.

Filion K, Powell DA, 2009. The use of restaurant inspection disclosure systems as a means of communicating food safety information. J Food Service 20:28797.

Garayoa R, Abundancia C, Díez-Leturia M, Vitas AI, 2017. Essential tools for food safety surveillance in catering services:
On-site inspections and control of high risk cross-contamination surfaces. Food Control 75:48-54.

Italian Parliament, 2007. Legislative Decree of 6 November 2007. [Attuazione della direttiva 2004/41/CE relativa ai controlli in materia di sicurezza alimentare e applicazione dei regolamenti comunitari nel medesimo settore, 193/2007] [Regulation in Italian]. In: Official Journal No. 261, 9/11/2007.

McDean HC, 1997. Dairy products. In: Whitten DO, Whitten BE, eds. Handbook of America Business history: extractives, manufacturing and service. Greenwood Publishing Group, Westport, CT, USA, pp 141-160.

Razzini K, Balzaretti CM, 2015. Premise to implement a grading system to evaluate the sanitary level in food service establishments in Milan, Italy. Ital J Food Safety 4:4514.

Zablotsky Kufel JS, Resnick BA, Fox MA, McGready J, Yager JP, Burke TA, 2011. The impact of local environmental health capacity on foodborne illness morbidity in Maryland. Am J Public Health 101:1495-500. 